\title{
Abrasive Slurry Erosion Behavior of Nitrile-Butadiene Rubber with Different Acrylonitrile Contents
}

\author{
Rui NIE*, Shijie WANG, Shuyuan SONG \\ School of Mechanical Engineering, Shenyang University of Technology, Shenyang 110870, PR China \\ crossref http://dx.doi.org/10.5755/j01.ms.26.1.20033
}

Received 26 January 2018; accepted 24 July 2018

\begin{abstract}
Nitrile-butadiene rubber (NBR) with different acrylonitrile contents were eroded by quartz slurry using a self-made erosion testing apparatus to study the erosion wear behavior. Quartz slurry with a concentration of $33 \mathrm{wt} . \%$ was used to impact the specimen surface at $45^{\circ}$ sample angle. The experimental data, such as erosion rate, hardness and swelling increment were compared and analyzed. The morphologies of worn surfaces were characterized using the field emission scanning electron microscopy to reveal the wear mechanism. The results showed that the acrylonitrile content in the molecular chains had a significant effect on the erosion performance of NBR. Furthermore, a static swelling test was conducted as a contrast experiment to investigate the effect of erosion on the swelling behavior of rubber surface. By comparing the results it could be found that the dynamic swelling increment during the erosion test was almost four or five times larger than that of static swelling. Mechanism of the interaction between swelling and erosion was also discussed.

Keywords: rubber, swelling, erosion wear, hardness, surface analysis.
\end{abstract}

\section{INTRODUCTION}

Slurry is generally defined as a mixture of liquid and solid particles that can be transported by pumping. Mineral separation and transportation in the form of slurry is an increasingly viable alternative in the mining industry. The main factor related to the expenses of such projects is wear. The wear environment, including mechanical wear and corrosion, dictates the initial capital, maintenance costs and service life of equipment [1-4]. Being a polymer, the nitrile-butadiene rubber (NBR) is well known in virtue of its high resistance to wear and corrosion [5,6]. Therefore, NBR is widely used to manufacture wear-resistant components in mining industry.

The tribological property of rubber-like material has been investigated by many researchers. However, more attentions in this field have been given to the friction and wear properties of materials, only a few studies relate to their erosion behavior. Ojala et al. [1] compared the wear behavior of rubber, polyurethanes and steels under slurry erosion condition. The results indicated that elastomers showed better wear resistance in low-stress abrasive erosion with the smallest particles. Arnold and Wood et al. [7-11] tested rubber and several elastomers to study their damage mechanisms under erosion. During the service life, some rubber-made components are not only eroded by particles, but also long-term exposed to liquid medium. Consequently, the role of swelling should also be taken into account when evaluating rubber properties. Mofidi et al. [12, 13] found that, after aging in various solutions, the wear resistance of NBR would reduce. According to the investigation of $\mathrm{Lv}$ [14], the wear volume of the NBR swelled in cyclohexane was more serious than that of an original one.

It can be indicated from the above studies and other researches $[15-18]$ that swelling-induced ageing of rubber in liquid is inevitable, such ageing behavior could gradually change the structure and degrade the mechanical property of rubber. Furthermore, the tribological behaviour could also promote swelling. Zuev et al. [19] found that the influence of aggressive medium could benefit from the mechanical actions.

Considering all the aforementioned, it is believed that the tribological failure of rubber in liquid medium could be attributed to a combined action of swelling-induced ageing and mechanical wear [20]. The interaction between them is well worth to be investigated. However, amongst all the researches related to the tribology of rubber, few scholars have studied the swelling or erosion behavior, and there is almost no reports about their interaction.

In the present investigation, three kinds of NBR with different acrylonitrile contents were eroded by quartz slurry to study their erosion wear behavior. A new erosion testing apparatus that can change various experimental parameters, such as particle sizes, slurry concentrations, sample angles and so on, was designed and built for the test. The swelling behavior and erosion resistance were investigated and the mechanism of their interaction was also revealed.

\section{EXPERIMENTAL}

\subsection{Testing apparatus}

Conventional erosion testers were investigated, it was found that most of the equipment were designed for metal. As generally known, there is great distinction in erosion mechanism between rubber and metal. As an elastomer, rubber is susceptible to deform while encountering impact. Beyond that, shortcomings, such as inflexible parameter adjustment, excessive cost and so on, could be found in the testers manufactured for eroding rubber.

\footnotetext{
${ }^{*}$ Corresponding author. Tel.: +86-13514202703.

E-mail address: nierui1996@126.com (R. Nie)
} 
According to the ASTM standards (G76-07 and G13406), a new slurry erosion apparatus was designed and built to test erosion wear properties of target materials for the present investigation. The schematic diagrams of the tester and nozzle are displayed in Fig. 1 and Fig. 2, respectively. The main characteristics of the erosion testing apparatus are as follow.

1. Experimental data at any angle could be obtained owing to the sample holder was attached to a rotating shaft;

2. Specimens could be fixed into a sample groove by two bolts to avoid error causing by the elastic deformation during the erosion process;

3. The volume and structure of the slurry tank and the power of the agitator motor were determined after strict design and accurate calculation in order to make the particles well-distributed in slurry and reduce the bottom deposition. The maximum permissible concentration of slurry is $40 \mathrm{wt} . \%$;

4. By adjusting the system pressure, the slurry velocity could be controlled freely from 0 to $25 \mathrm{~m} / \mathrm{s}$;

5. A visualization window was designed for the sample room to facilitate real-time observation of experiment;

6. The nozzle could be replaced to meet varied test requirements.

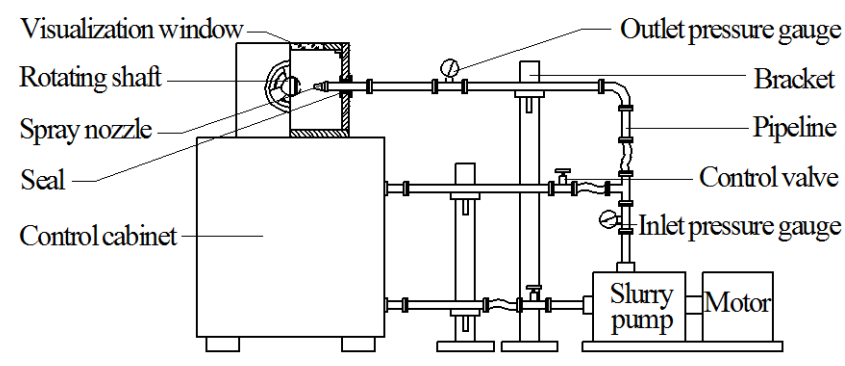

a

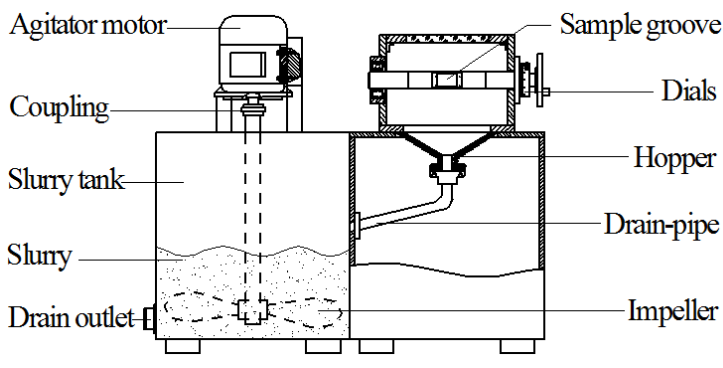

$\mathrm{b}$

Fig. 1. Schematic diagram of erosion tester: $a-$ front view; $b-$ left view

\subsection{Materials}

The materials selected for the investigation were three kinds of NBR with different acrylonitrile contents, $18 \mathrm{wt} . \%$, 26 wt.\% and 41 wt.\% (abbreviated as N18, N26 and N41, respectively). The NBR specimens were made in a laboratory based on the masterbatch produced by Lanzhou Petroleum and Chemical Company in China. The main chemical compositions and their weight fraction are listed in Table 1.

After plasticizing on open roll mill, various ingredients were added to masterbatch for mixing. Mixed compound was finally vulcanized using press vulcanizer. The special mould was used to press the blend into blocks with the size of $40 \mathrm{~mm} \times 25 \mathrm{~mm} \times 6 \mathrm{~mm}$. The hardness of NBR specimens were controlled between 70 and 80 Shore A. The fabrication procedure is shown in Fig. 3.

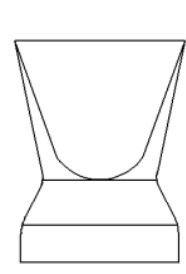

a

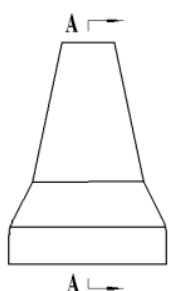

b

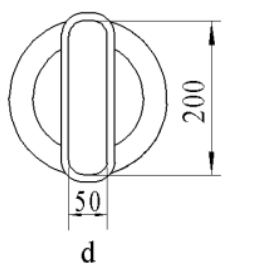

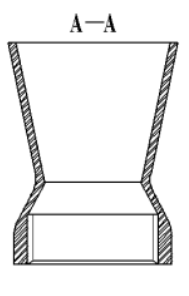

c
Fig. 2. Schematic diagram of nozzle, size of the outlet is $200 \mathrm{~mm} \times 50 \mathrm{~mm}$ : a-front view; b-left view; $\mathrm{c}-$ sectional view; $\mathrm{d}-$ vertical view

Table 1. Main chemical compositions of experimental materials

\begin{tabular}{|l|c|}
\hline \multicolumn{1}{|c|}{ Main component } & Mass fraction, phr \\
\hline Masterbatch & 100 \\
\hline Carbon black & 70 \\
\hline Vulcanizing agent & 3 \\
\hline Activating agent & 12 \\
\hline Accelerating agent & 4 \\
\hline Anti-aging agent & 5 \\
\hline
\end{tabular}

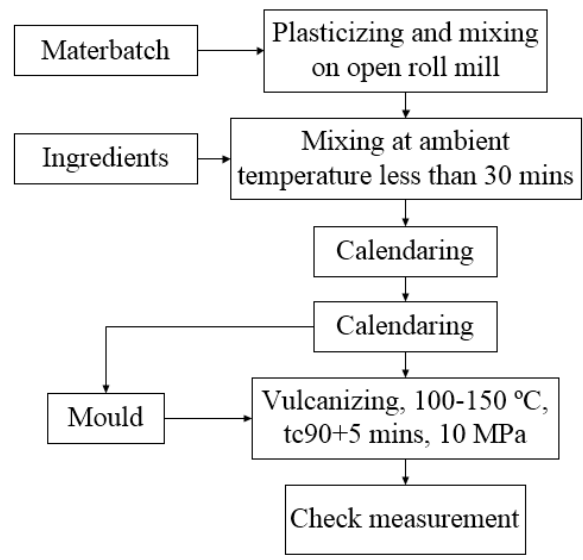

Fig. 3. Flow chart of fabrication of NBR specimens

\subsection{Abrasive slurry}

Angular and irregular quartz sand with a size of 20-40 mesh and a hardness of 7 on the Mohs' scale was selected as erodent particles; Fig. 4 shows its morphology. $33 \mathrm{~kg}$ quartz sand and $67 \mathrm{~kg}$ water (deionized water, industrial grade) were mixed into quartz slurry with a concentration of $33 \mathrm{wt} . \%$. The quartz slurry was changed after each test to minimize the mutual impact of particles.

\subsection{Erosion test}

Erosion tests were carried out according to the standard (GB/T 12584-2008). Specimens were mounted into the 
sample groove with a horizontal distance of $50 \mathrm{~mm}$ from the end of the nozzle to the testing surface, and the sample angle was adjusted at $45^{\circ}$. The slurry velocity was controlled around $22.8 \mathrm{~m} / \mathrm{s}$. Before and after each test, every specimen was dried in an oven at $90{ }^{\circ} \mathrm{C}$ for $2 \mathrm{~h}$ to avoid the influence of absorbed water on its weight. The specimens were weighed on an electronic scale with a precision of $0.1 \mathrm{mg}$ both before and after dried. The weight loss was calculated, each datum was an average of 5 repeated test values.

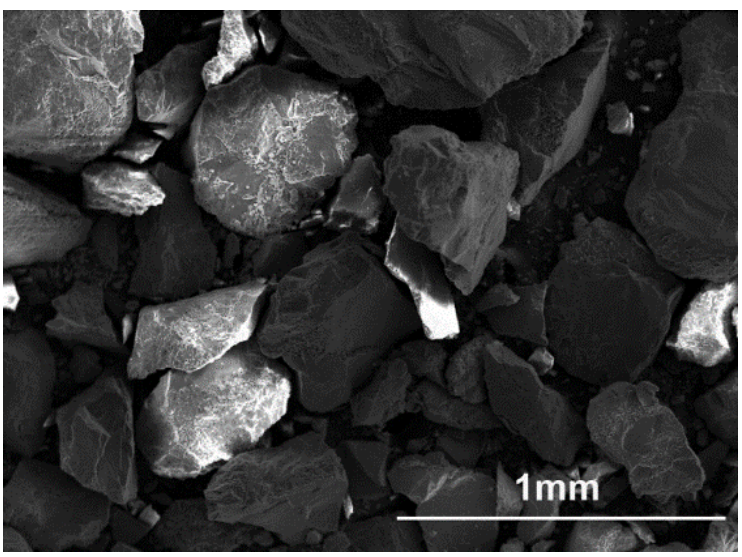

Fig. 4. Scanning electron micrograph of erodent particles

It is more accurate to calculate erosion rate by volumetric loss than by mass loss when the specimens have different densities and different swelling characteristics, as proposed by Finnie [21]. During the erosion period, more particles impact on the surface of the specimens would remove more material from the surface, and the mass remove per seconds depend on the total amounts of particles $[22,23]$, the formula of erosion rate is as follow:

Volumetric removal per second, $\mathrm{cm}^{3} / \mathrm{s}$

$=\frac{\text { Mass removal per second, } \mathrm{g} / \mathrm{s}}{\text { Average density, } \mathrm{g} / \mathrm{cm}^{3}}$

Erosion rate, $\mathrm{cm}^{3} / \mathrm{kg}$

$$
=\frac{\text { Volumetric removal per second }\left(\mathrm{cm}^{3} / \mathrm{s}\right)}{\text { Mass amounts of impact particles per second }(\mathrm{kg} / \mathrm{s})}
$$

The morphology of the particles and the surface of the eroded specimens were observed by the SU8010 field emission scanning electron microscopy (FESEM), Hitachi Ltd., Japan. After cleaning treatment, the worn surface of the specimen was coated with a thin layer of carbon by sputtering. The micrograph was obtained at an accelerating voltage of $10 \mathrm{kV}$.

\section{RESULTS AND DISCUSSION}

\subsection{Repeatability of the erosion testing apparatus}

To confirm the repeatability, five pieces of N26 specimens were tested by the tester under the same condition, the test variables are listed in Table 2. After being calculated, the average value of erosion rates is $9.42 \mathrm{~cm}^{3} / \mathrm{kg}$, and the standard deviation is 0.32 . It could be found that the erosion rates were closed enough to confirm the repeatability of this tester was satisfactory. Thus, the utilization of this tester was an effective way to investigate the slurry erosion behavior of NBR specimen.

Table 2. Erosion test condition

\begin{tabular}{|l|c|}
\hline \multicolumn{1}{|c|}{ Test variable } & Mass fraction \\
\hline Sample angle $\alpha,^{\circ}$ & 45 \\
\hline Test duration $\mathrm{t}, \mathrm{h}$ & 4 \\
\hline Slurry concentration, wt. $\%$ & 33 \\
\hline Slurry velocity $\mathrm{V}, \mathrm{m} / \mathrm{s}$ & 22.8 \\
\hline Erodent particle loading L, kg & 33 \\
\hline Water loading L, kg & 67 \\
\hline Erodent particle & Silica sand (20-40 mesh) \\
\hline Temperature T, $\mathrm{K}$ & Ambient temperature \\
\hline
\end{tabular}

\subsection{Results of erosion tests}

In order to examine erosion behavior of NBR in abrasive slurry, erosion tests on three kinds of materials were carried out by the tester, the test conditions were the same with that listed in Table 2. Fig. 5 shows their erosion rates; each value is the average value of 5 repeated tests. It can be seen that N18 was the most eroded, and among them, the erosion rates of $\mathrm{N} 41$ was the lowest. The erosion rate decreased with the increasing of the acrylonitrile content in the molecular chains of this 3 kinds of NBR specimens, which means under experimental condition, acrylonitrile improved the erosion performance of NBR.

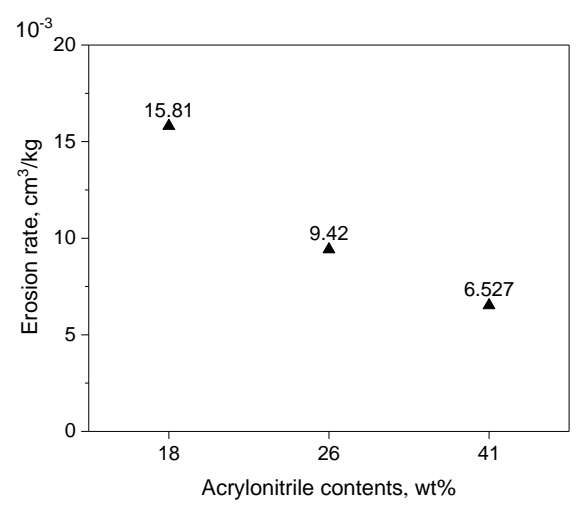

Fig. 5. Erosion rate of 3 kinds of specimens at sample angle of $45^{\circ}$

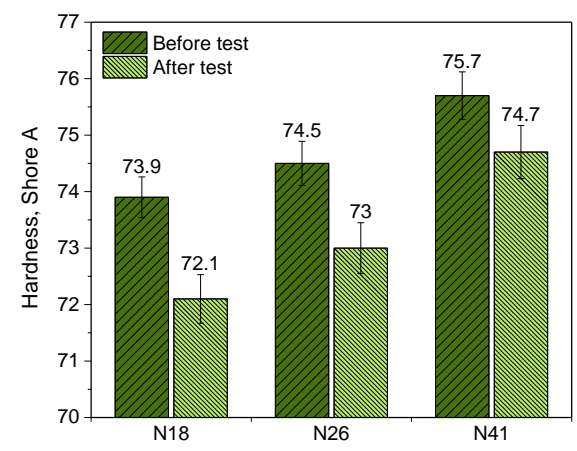

Fig. 6. Shore A hardness of NBR specimens before and after test

Fig. 6 shows the Shore A hardness of the three kinds of NBR specimens both before and after test, each test was repeated 5 times to indicate the error bar of standard deviation. As a result, the hardness of NBR specimens showed an increase tendency with the growth of acrylonitrile content both before and after test. For each kind of specimen, the hardness decreased after test, and it is notable that the descent rate reduces with increasing of their 
acrylonitrile content, the values were $2.44 \%, 2.01 \%$ and $1.32 \%$, respectively.

\subsection{Worn surface observation and wear mechanism analyses}

To better reveal the erosion behavior of NBR under abrasive slurry erosion, the wear marks were observed by FESEM. Fig. 7 gives the worn surface morphologies, after blasting for 4 hours, pitting, holes and lamellar spalling were intuitively exhibited in these morphologies. Obviously, the surface of N18 was eroded more seriously than that of N26 and N41, and it was almost entirely spalled, larger holes, tears and lamellar spalling appeared. While the worn surface of N41 was relatively smooth, only mild pitting and few lamellar spalling could be observed. This directly proved that the erosion rate of N41 in abrasive slurry erosion was lower than that of $\mathrm{N} 18$, as shown in Fig. 5. It could be indicated that, under experimental condition, the erosion resistance increased with the increasing of the acrylonitrile content, which means acrylonitrile improved erosion performance of NBR.

Apart from the spalling and pitting, tooth-typed grooves can also be observed in Fig. 7. This is evidently due to NBR specimens were cut and torn by the quartz particles with high speed and sharp tips during erosion process, furthermore, the particles have much higher hardness than the NBR specimens. This mechanism had been observed by other researchers [7-10].

\subsection{Interaction between swelling and erosion}

The molecular chains in vulcanized rubber are usually loosely gathered, and there are large gaps in the molecular network. Aggressive medium can penetrate into these gaps leading to volume expansion and weight increase, this is the swelling phenomenon of rubber [14]. As the carrier of erodent particles, the liquid medium could infiltrate into the rubber during erosion process, causing the dynamic swelling of rubber, which will make the rubber aged and further affected the tribological properties [24, 25]. The investigations of $\mathrm{Lv}$ et al. [16,19] showed that after swelling, the wear performance of NBR reduced, the hardness decreased, and the surface damage became more serious. Ch'ng [25] reported that the amount of swelling of rubber in solvent is affected by loading. During the erosion test, the surface of NBR specimen was acted upon by impulsive force caused by the impact of slurry with a certain amount of kinetic energy, which met the conditions of swelling increment presented by Ch'ng. Thus it can be seen that not only swelling can affect the tribological properties of rubber, but also erosion behavior can increase the amount of swelling. Therefore, it is essential to understand the interaction between swelling and erosion wear behavior of rubber.

A static swelling test was conducted as a contrast experiment to investigate the effect of erosion on rubber swelling. Dynamic and static swelling increment of three kinds of NBR specimens are shown in Fig. 8. The dynamic increment data were collected in accordance with the experimental conditions shown in Table 2, and the static swelling data was acquired after immersing the NBR specimens in deionized water for $4 \mathrm{~h}$ at ambient temperature and pressure. The dynamic swelling increment that generated during the erosion test was almost four to eight times larger than the increments of static swelling in immersion experiment, it proved that erosion behavior did increase the swelling amount of NBR specimens.

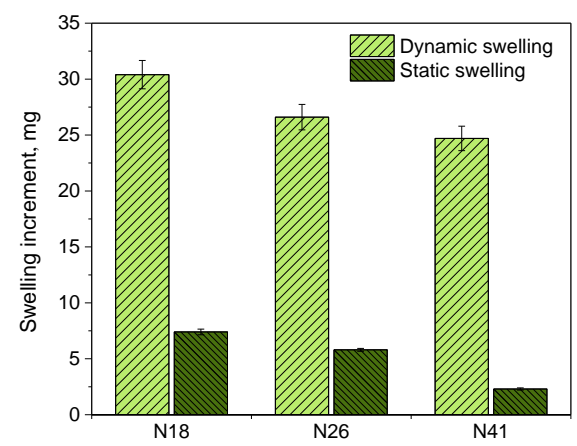

Fig. 8. Dynamic and static swelling increment of NBR specimen, the error bars indicate the standard deviation of the results

Under the impact of slurry, defects such as cracks, pitting, holes and so on gradually appeared on the surface of specimens, as shown in Fig. 9 a. The defects made the surface worn in the form of lamellar spalling and formed the ridge pattern with a sharp top, as shown in Fig. 9 b. Fig. 9 c shows the swelling morphology of N26, it is clearly that water swelling of worn surface is more serious than the surface without any abrasion. That is due to the impulsive force of slurry not only compressed the specimen surface, but also extruded the liquid medium to make it infiltrate into rubber surface. And the lamellar spalling and ridge pattern increased the contact area between worn surface and slurry, making the liquid medium infiltrate into rubber surface more easily and leading to the increase of dynamic swelling increment. The swelling further weakened the surface properties and made rubber surface easier to be torn out.

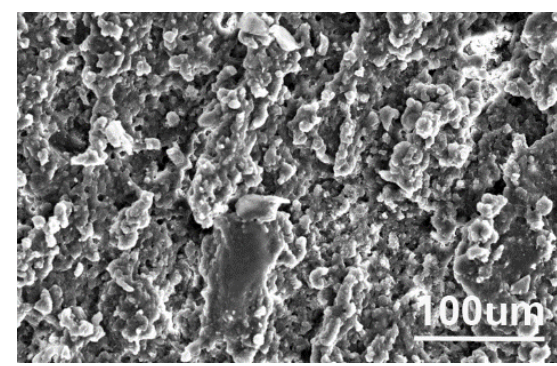

a

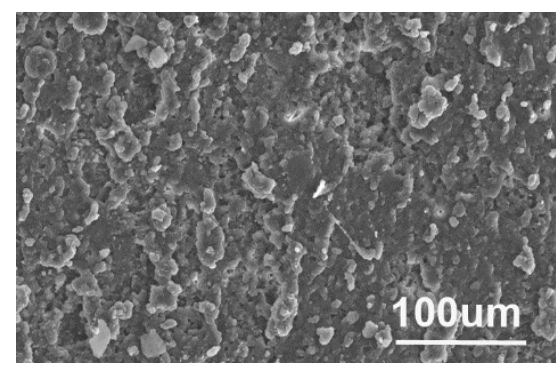

b

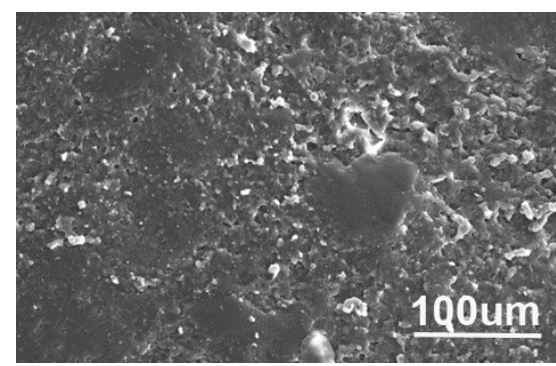

$\mathrm{c}$

Fig. 7. Worn surface morphologies of three kinds of NBR specimens eroded by quartz slurry at $45^{\circ}, 3600$ s: $a-N 18$; b - N26; c $-\mathrm{N} 41$ 


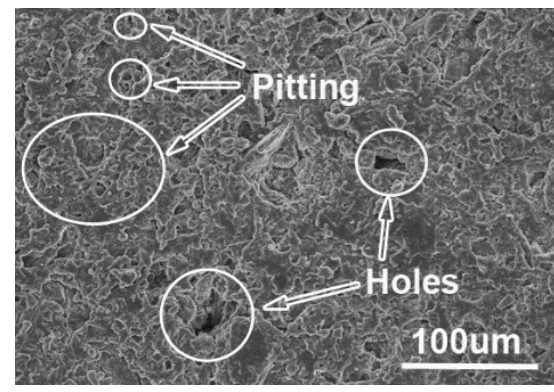

a

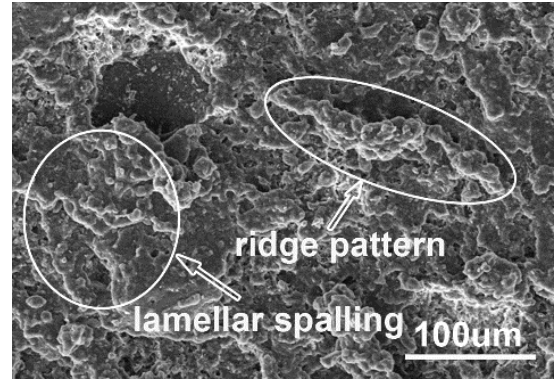

b

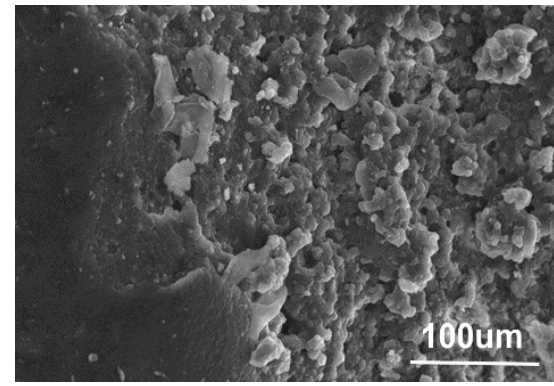

c

Fig. 9. Morphologies of defects of NBR specimens after erosion test: $a$ - pitting and holes of N26; $b$-ridge pattern and lamellar spalling of N18; c-swelling of N26

\subsection{A discussion on erosion behaviors of NBR}

When erosion test began, the surface of NBR specimen was impacted and acted upon by impulsive force caused by the slurry with a certain amount of kinetic energy. The impulsive force led to compressive force acting on the surface of specimen, which could be divided into two components that were the stress caused by water and the stress caused by solid particles. So the stress state of specimen surface in the erosion tests was repeating compression stress caused by water and periodic pressing and relaxing due to the impact of solid particles. The former made the surface swell, while the latter made the surface erode.

Fig. 10 gives the formation process of rubber eroded by solid particles. At first, under the impact of particles, surface deformed and cracks appeared. When the deformation area was impacted by subsequent particles, the cracks grew, the deformation aggravated and the tongue formed. The creation of the debris was due to the tongue was broken off by subsequent shocks. The two processes, surface damage (including the growth of crack and the formation of tongue) and break of the tongue, periodically generated on the surface of NBR specimens under the repeated actions of compressive and shear force caused by slurry.

When the first layer of rubber surface was eroded by particles, the internal structure would be directly exposed to the impact of slurry. The liquid penetrated into molecular network of rubber could further extend the molecular chains, increased the distance between the chain segments and destroyed the molecular network, that would allow more liquid to enter into the rubber and was also the reason why the hardness of NBR specimens decreased after test, as shown in Fig. 7. Therefore, the tribological properties of swelled specimens could gradually reduce, meanwhile, the cracks were more easily to be generated and extended by surface compressive stress and surface shear stress. These cracks not only increased the amount of surface damage, but also shortened the time of damage generation and propagation. When the cracks expanded large enough, another layer would be broken off from rubber surface in a lamellar form. Thus, the worn surface of NBR specimen was peeled off from layer after layer.

Compared with the swelling and erosion behaviors of three kinds of NBR specimens, it could be found that the rubber with higher acrylonitrile content had higher hardness, better erosion resistance and better swelling resistance, as shown in Fig. 6, Fig. 5, and Fig. 9, respectively. The reason is that the cohesive energy density and the solubility parameter of NBR were strengthened with the increasing of acrylonitrile content in the molecular chains [26]. As a hard monomer and a polar monomer, acrylonitrile can form hydrogen bonds and adequately combine with reinforcing carbon black that makes the crosslinking network of rubber denser. Thereby the intermolecular forces and the difficulty of internal rotation within molecular chain are both strengthened by the increasing content of acrylonitrile, which explained the hardness descent rate of $\mathrm{N} 41$ after being eroded was smaller than that of N18 and N26, as mentioned in Results of Erosion Tests Section.

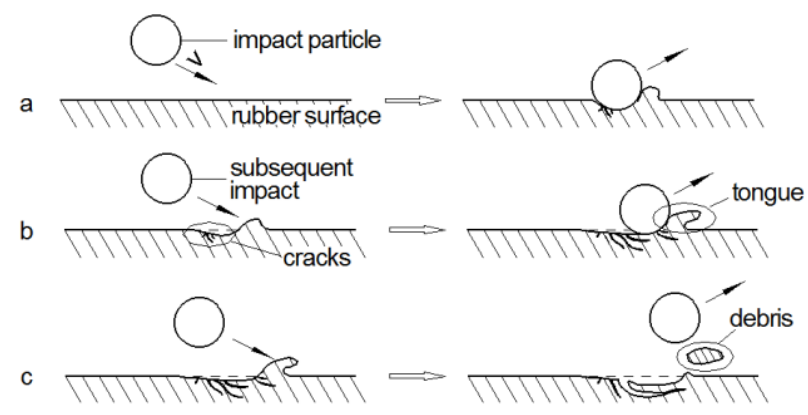

Fig. 10. Formation process of rubber erosion: a-surface deform and cracks appear; b-cracks grow, deformation aggravate and tongue form; $\mathrm{c}$ - debris appear

\section{CONCLUSIONS}

This study has investigated the wear behavior of NBR with different acrylonitrile contents in abrasive slurry erosion. Based on the above results and discussions, the following conclusions can be drawn:

1. A new erosion testing apparatus was designed and built, the results obtained by it was proved to be repeatable.

2. The improvement of the erosion performance of NBR specimens should be attributed to the acrylonitrile increased the hardness rather than change the wear mechanism. The hardness decreased after test, however the descent rate reduce with the increasing of their acrylonitrile content, the values were $2.44 \%, 2.01 \%$ and $1.32 \%$, respectively.

3. The influences of erosion behavior on the swelling increment of NBR specimens was proved by a contrast test, the dynamic swelling increment durning the 
erosion test was 4 to 8 times larger than that of static swelling.

4. The interaction between swelling and erosion was discussed, and the surface damage process of NBR under abrasive slurry erosion was analysed.

\section{Acknowledgments}

This work is supported by the Program for Liaoning Innovative Research Team in University-LNIRT (LT2014003).

\section{REFERENCES}

1. Ojala, K., Valtonen, K., Antikainen, A., Kemppainen, A., Minkkinen Oja, O., Kuokkala, V.T. Wear Performance of Quenched Wear Resistant Steels in Abrasive Slurry Erosion Wear 354-355 2016: pp. 21-31.

https://doi.org/10.1016/j.wear.2016.02.019

2. Tan, Y., Zhang, H., Yang, D., Jiang, S., Song, J., Sheng, Y. Numerical Simulation of Concrete Pumping Process and Investigation of Wear Mechanism of the Piping Wall Tribology International 46 2011: pp. 137-144. https://doi.org/10.1016/j.triboint.2011.06.005

3. Gittins, L. Hydraulic Transport of Solids - Wear in Slurry Pipelines. BHRA Fluid Engineering, UK, 1980.

4. Truscott, G.F. Wear in Pumps and Pipelines. BHRA Fluid Engineering, UK, 1980.

5. Liang, L., Zhao, S.H., Zhu, L.L., Yao, C. Properties and Compression Morphological Characteristics of Hydrogenated Nitrile Rubber Filled with Nano-Fillers China Synthetic Rubber Industry 35 2012: pp. 17-21.

https://doi.org/10.3969/j.issn.1000-1255.2012.01.004

6. Dong, C.L., Yuan, C.Q., Bai, X.Q., Yan, X.P., Peng, Z. Tribological Properties of Aged Nitrile Butadiene Rubber under Dry Sliding Conditions Wear 322-323 2015: pp. 226-237.

https://doi.org/10.1016/j.wear.2014.11.010

7. Arnold, J.C., Hutchings, I.M. The Mechanisms of Erosion of Unfilled Elastomers by Solid Particle Impact Wear 138 1990: pp. $33-46$. https://doi.org/10.1016/0043-1648(90)90166-8

8. Arnold, J.C., Hutchings, I.M. A Model for the Erosive Wear of Rubber at Oblique Impact Angles Journal of Physics D-Applied Physics 25 1992: pp. A222-A229. https://doi.org/10.1088/0022-3727/25/1A/034

9. Arnold, J.C., Hutchings, I.M. Erosive Wear of Rubber by Solid Particles at Normal Incidence Wear 161 1993: pp. $213-221$. https://doi.org/10.1016/0043-1648(93)90472-X

10. Arnold, J.C. Impact of Small Particles onto Rubber Surfaces at Glancing Angles Journal of Applied Polymer Science 64 1990: pp. 2199-2210.

11. Wood, R.J.K., Puget, Y., Trethewey, K.R., Stokes, K. The Performance of Marine Coatings and Pipe Materials under Fluid-Borne Sand Erosion Wear 219 1998: pp. 46-59. https://doi.org/10.1016/S0043-1648(98)00231-2

12. Mofidi, M., Kassfeldt, E., Prakash, B. Tribological Behavior of an Elastomer Aged in Different Oils Tribology International 41 2008: pp. 860-866. https://doi.org/10.1016/j.triboint.2007.11.013
13. Mofidi, M., Prakash, B. The Influence of Lubrication on Two-Body Abrasive Wear of Sealing Elastomers under Reciprocating Sliding Conditions Journal of Elastomers and Plastics 43 2011: pp. 19-31. https://doi.org/10.1177/0095244310385435

14. Lv, X.R., Wang, H.M., Wang, S.J. Effect of Swelling Nitrile Rubber in Cyclohexane on its Ageing, Friction and Wear Characteristics Wear 328-329 2015: pp. 414-421. https://doi.org/10.1016/j.wear.2015.03.016

15. Torbacke, M., Johansson, A. Seal Material and Base Fluid Compatibility: An Overview Journal of Synthetic Lubrication 22 (2) 2005: pp. 123-142. https://doi.org/10.1002/js1.2005.22.2.123

16. Simson, T., Kulu, P., Surzenkov, A., Tarbe, R., Goljandin, D., Tarraste, M., Viljus, M., Traksmaa, R. Wear Resistance of Sintered Composite Hardfacings under Different Abrasive Wear Conditions Materials Science (Medžiagotyra) 23 (3) 2017: pp. 249-253. https://doi.org/10.5755/j01.ms.23.3.17640

17. Lv, X.R., Song, S.Y., Wang, H.M., Wang, S.J. Effect of $\mathrm{CO}_{2}$ Gas on the Swelling and Tribological Behaviors of NBR Rubber in Water Journal of Material Science \& Technology 31 2015: pp. $1282-1288$. https://doi.org/10.1016/j.jmst.2015.09.014

18. Ridgway, N., Colby, C.B., O’Neill, B. Slurry Pump Gland Seal Wear Tribology International 42 2009: pp. $1715-1721$. https://doi.org/10.1016/j.triboint.2009.04.047

19. Zuev, Y.S., Chelmodeev, A.D. Effect of Mechanical Factors on Rubber Wear in Aggressive Media Mekhanika Polimerov 4 (3) 1968: pp. 499-503. https://doi.org/10.1007/BF00859534

20. Walker, C.I., Robbie, P. Comparison of Some Laboratory Wear Tests and Field Wear in Slurry Pumps Wear $302(1-2)$ 2013: pp. 1026-1034. https://doi.org/10.1016/j.wear.2012.11.053

21. Finnie, I. Erosion of Surface by Solid Particles Wear 3 1960: pp. $87-103$. https://doi.org/10.1016/0043-1648(60)90055-7

22. Yaer, X., Shimizu, K., Matsumoto, H. Erosive Wear Characteristic of Spheroidal Carbides Cast Iron Wear 264 2008: pp. $947-957$. https://doi.org/10.1016/j.wear.2007.07.002

23. Shimizu, K., Yaer, X., Araya, S. Solid Particle Erosion and Mechanical Properties of Stainless Steels at Elevated Temperature Wear 271 2011: pp. 1357-1364. https://doi.org/10.1016/j.wear.2010.12.038

24. Fukumori, K., Kurauchi, T., Kamigaito, O. Swelling Behaviour of Rubber Vulcanizates: 2. Effects of Tensile Strain on Swelling Polymer 31 (12) 1990: pp. 2361-2367. https://doi.org/10.1016/0032-3861(90)90325-S

25. Ch'ng, S.Y., Andriyana, A., Verron, E., Kahbasi, O., Ahmad, R. Development of a Novel Experimental Device to Investigate Swelling of Elastomers in Biodiesel Undergoing Multiaxial Large Deformation Experimental Mechanics 53 2013: pp. $1323-1332$. https://doi.org/10.1007/s11340-013-9737-2

26. Yasin, T., Ahmed, S., Yoshii, F., Makuuchi, K. Effect of Acrylonitrile Content on Physical Properties of Electron Beam Irradiated Acrylonitrile-Butadiene Rubber Reactive and Functional Polymers 57 2003: pp. 113-118. https://doi.org/10.1016/j.reactfunctpolym.2003.08.004 